Working Paper 04-48

Business Economics Series 16

October 2004
Departamento de Economía de la Empresa

Universidad Carlos III de Madrid

Calle Madrid, 126

28903 Getafe (Spain)

Fax (34-91) 6249608

\title{
Product Strategies and Startups' Survival in Turbulent INDUSTRIES: EVIDENCE FROM THE SECURITY SOFTWARE INDUSTRY
}

\author{
Andrea Fosfuri ${ }^{1}$ and Marco S. Giarratana ${ }^{2 *}$
}

\begin{abstract}
This paper seeks to explore the drivers of startups' survival in turbulent industries, characterized by high rates of entry and exit, fragmented market shares, and a rapid pace of product innovation. Specifically, the paper aims to underscore the role played by post-entry product strategies, along with their interaction, beyond that of pre-entry conditions. Based on a sample of 270 startups that entered the Security Software Industry from 1989 till 1998, we find evidence that surviving entities are those that more aggressively adopt versioning and product portfolio strategies. Interesting enough, strategic learning seems to play a major role: Focusing on one of the two product strategies commands a higher survival probability than adopting a mixed strategy.
\end{abstract}

Keywords: Startups, Survival, Product Strategies, Turbulent Industries

JEL: L86, O32, M13

\footnotetext{
* We gratefully acknowledge financial support from the European Commission (HPSE-CT-2002-00146), and the Spanish Ministry of Science and Technology (SEC2003-03797). We thank Elisabeth Cabrera, Bruno Cassiman, Julio de Castro, Paola Giuri, Isabel Gutierrez, seminar participants at the Instituto de Empresa (Madrid), at the $2^{\text {nd }}$ Econ-Change workshop (London) and at the $10^{\text {th }}$ ISS Conference (Milan) for helpful comments and suggestions on an earlier draft. The usual disclaimer applies.

${ }^{1}$ Universidad Carlos III de Madrid. Department of Business Administration. Calle Madrid 126. 28903 Getafe Madrid.Spain andrea.fosfuri@uc3m.es

${ }^{2}$ Universidad Carlos III de Madrid. Department of Business Administration. Calle Madrid 126. 28903 Getafe Madrid, Spain. marco.giarratana@uc3m.es
} 


\section{INTRODUCTION}

The crucial role of entrepreneurship as a source of innovation and economic growth has been emphasized by Schumpeter since the 1930s (Schumpeter, 1934). More recently, the analysis of small and young firms has attracted increasing attention given the well-known difficulties of established firms to successfully compete in industries characterized by radical innovation and technological change (Tushman and Anderson, 1986; Henderson and Clark, 1990; Tripsas and Gavetti, 2000). As a consequence, a large body of the managerial and economic literature has focused on understanding the reasons underpinning the creation of new firms and the drivers of their success, especially in technology-based industries (Shane, 2001; Gans and Stern, 2003).

This paper follows in this tradition, and attempts to shed novel evidence on the drivers of startups' survival in turbulent industries, which are defined as industries where entry and exit barriers are small, economies of scale play a marginal role, and firms' competences and strategies are placed under a fierce process of selection (Covin and Slevin, 1989; Schmanlensee, 2000). Examples include the laser industry, the hard disk drive industry, semiconductors and biotechnology (Klepper, 2002; McKendrick et al., 2003; Barnett and Freeman, 2001).

Specifically, the contribution of this research is to underscore the impact of post-entry strategies on startups' survival beyond that of pre-entry factors and initial conditions, which have been identified as determinants of startups' survival by the existing literature (see for instance, Klepper, 2002). The focus on post-entry strategies becomes crucial in turbulent industries where firms that rest on their laurels, i.e. pre-entry factors and initial conditions, are condemned to a premature exit. It is worth noting that the analysis of post-entry strategies by startups is rather rare in the literature (see recently Stern and Henderson, 2004). There is a clear reason: When dealing with startups, data are difficult to collect and they are scarcely cooperative. As a consequence, little is known about this issue. This work aims to fill this gap by relying on a novel self-assembled dataset on products introduction in the Security Software Industry (SSI), a relatively recent segment of the software industry.

SSI represents a prototypical example of turbulent industries and an interesting test-bed for several reasons: i) it is a technology-based industry where product innovation plays a major 
role; ii) since its inception, it has displayed an astonishing level of entry and exit, with little sign of consolidation around a few large players; iii) entry and exit barriers as well as scale economies are rather low; iv) competition takes place mostly among startups, whereas incumbent firms are marginal players. ${ }^{1}$

Building upon the product life cycle theory (Abernathy and Utterback, 1978) we argue that in turbulent industries pre-entry factors and initial conditions might be less useful in explaining survival than they are in more stable industries. By contrast, post-entry strategies, i.e. the moves, actions, decisions taken after entry, become critical to guarantee the long term success of the new entity. Specifically, we focus on the post-entry strategies pursued in the product space, which are likely to be crucial in high-tech industries where the pace of product innovation is extremely high. Drawing on a sample of 270 startups that have entered our reference industry since its birth in 1989, we find evidence that surviving startups are those that actively increase the scope of their product portfolio or adopt an aggressive mono-niche versioning strategy. Moreover, focusing either on a versioning strategy or a product portfolio strategy commands a higher survival probability than adopting a mixed strategy. So, stable strategic orientation helps startups increase their survival probability. We find this result in line with the strategic learning literature (Kuwada, 1998). Interestingly enough, other things being equal, early entrants do not command a significantly higher likelihood of surviving, whereas technological capabilities play an important role.

This paper is related to several streams of literature. Some research on startups has focused on the reasons behind firm creation. Indeed, firm formation has been associated with industry-level factors, such as market structure (Audretsch, 1991), technology regimes (Winter, 1984) and technological opportunities (Shane, 2001) or with individual-level factors, such as the psychology of entrepreneurs (Roberts, 1991) and career experience (Carroll and Masakowski, 1987). In this paper our attention moves from the factors that support firm creation to those that foster startup survival. In turbulent environments, the real challenge for young firms with scarce initial financial and organizational resources, resides in how they are able to turn into a profit the idea that pushed entry (Bhide, 2000). 
While several investigations have already studied industry-level determinants of survival, such as sector characteristics, IPRs regimes, availability of venture capital, etc. (Gans and Stern, 2003; Chesbrough, 2000), much less is known about firm-specific drivers of survival. The only robust "historical" result on which the literature agrees is that survival is directly influenced by firm age and size (Wagner, 1994; Mata and Machado, 1996). But dealing with startups, size and age represent far too a grainy lens. Recently, some authors have highlighted the role of initial capabilities (differently measured) and entry timing as the two most important determinants of startups' survival (Klepper, 2002). As a step further, our research aims to underscore the impact of post-entry product strategies beyond that of pre-entry controls on the likelihood of startups' survival in an industry where entry barriers and scale economies are small.

From a different tradition, population ecologists have also analyzed the impact of product strategies on firms' survival probability (Sorenson, 2000; Dobrev et al., 2001; Barnett and Freeman, 2001). For instance, Sorenson (2000) considers the interaction between product strategy and environmental turbulence, whereas Barnett and Freeman (2001) distinguish between the static and the dynamic effects of product introduction. This stream of research has typically focused on industries dominated by large diversified firms (e.g. cars, workstations, etc.) and has overlooked the role played by firm-specific pre-entry conditions, which have been the major concern of the traditional industrial organization perspective discussed above.

Our paper constitutes therefore an attempt to test simultaneously for the validity of the two traditions using as a test-bed a young industry where the dominant organizational form is the new venture.

Finally, this article provides one of the few systematic empirical studies aimed at understanding the drivers of startups' survival in turbulent environments, where large and established firms find difficult to flourish (Hall, 1980; Covin and Slevin, 1989; D’Aveni, 1994; Thomas, 1996). Other notable exceptions are Lieberman (2003) who focuses on the Dot-Com sector and Makadok (1998) who studies the money market mutual fund industry. One virtue of our paper is that we have managed to assemble a dataset that covers the whole history of SSI since its birth 
in 1989, with a comprehensive account of different strategic moves in the product space by virtually all the industry players.

The remainder of the paper is organized as follows. The next section builds the theoretical background and derives our hypotheses. Section 3 takes a brief detour into the salient traits of SSI, and describes the sample and the methodology. Section 4 discusses our findings and section 5 concludes the paper.

\section{THEORETICAL BACKGROUND AND HYPOTHESES}

Following the seminal work of William J. Abernathy and James M. Utterback (1978), several scholars have focused their attention on the way industries evolve and its implications for strategy. Most industries are believed to follow an evolutionary pattern known as the "product life cycle". A salient characteristic of this pattern is that after an initial period of very intensive entry and exit, and highly fragmented market shares, the industry is subject to a "shake-out" phase, which leads to higher concentration, fewer opportunities to improve the products and the emergence of a dominant design (Klepper, 2002; Geroski, 1995). Indeed, with the aim to reduce production costs, the focus of firms' rivalry shifts from product to process innovation. This obliges the firms to invest more in capital-intensive methods of production, which reinforces the shake-out of producers by increasing the minimum efficient size firm. In this phase of the product life cycle, scale economies and learning effects overtake any competitive advantage stemming from innovation of de-novo entrants. Empirical research has demonstrated that in shake-out environments initial capabilities, time of entry and exploitation of scale and learning economies are the most important determinants of firms' survival (Klepper, 2002).

Some recent evidence has however highlighted that the pattern described above is not as ubiquitous as it has been initially suggested. The laser industry, the hard disk drive industry, semiconductors and biotechnology offer good examples of how entry and exit rates remain intense during the whole industry life (McKendrick et al., 2003; Barnett and Freeman, 2001). In addition, in recent years, some industries have evolved from oligopolistic stable environments to turbulent ones (Lampel and Shamsie, 2003). Such tumultuous industries are characterized by 
low access barriers and by a very fragmented market structure. Consequently, they tend to display high rates of entry and exit that do not level off. Product innovation plays a crucial role, whereas process innovation tends to be of minor importance since competitive advantages can hardly be grounded on cost benefits. New versions and product categories proliferate rapidly making obsolete old established product generations. Since there is little investment in capitalintensive methods of production, the minimum efficient size of the firm can be small and shakeout phases do not need to materialize. In the literature, this typology of industries, that we label turbulent, goes usually under different names, like hypercompetitive (D’Aveni, 1994), hostile (Covin and Slevin, 1989) and Schumpeterian (Schmalensee, 2000).

This distinction between shake-out and turbulent industries, although painted with a broad brush, it helps highlight the important differences in strategic conduct between the two. In shake-out industries, the role of management is to build and defend a long-term sustainable advantage. As the evidence suggests, superior performances in these industries are most likely to be driven by cost advantages based on the exploitation of scale economies with pre-entry factors like entry time and initial capabilities playing a crucial role. By contrast, in turbulent industries, there is "a fundamental shift in the rules of competition and the way the game of competition is played" (Ilinitch, D'Aveni and Lewin, 1996). Successful firms need to continuously renew their competitive advantage and rely on dynamic capabilities (Teece et al., 1997). By creating a constantly changing series of small, temporary competitive advantages, firms manage to keep competitors off balance by forcing them to respond (Makadok, 1998).

Although the existing literature on shake-out industries has provided quite a lot of evidence on the importance of pre-entry factors and initial conditions for the survival of firms (Klepper, 2002), it has downplayed the role of post-entry strategies, i.e. the moves, actions, decisions taken after entry. Post-entry strategies are particularly important in turbulent industries where firms that rest on their laurels are condemned to a premature exit. In this paper, we focus on this understudied portion of the literature. Precisely, we aim at quantifying the impact of post-entry strategies beyond that of initial conditions, pre-entry factors and other possible ex-ante 
determinants of survival in an industry where the rate of turbulence does not seem to diminish across time.

We will focus on the post-entry strategies pursued by startups in the product space, and their interaction. Our decision to choose product strategies is twofold. First, product introduction represents a measurable and visible (especially for competitors) realization of the firm's strategy, and so it takes a primary position inside the range of strategic moves of a company (Siggelkow, 2003). Second, product strategies are extremely important for new ventures that usually build their reputation on the type of products they introduce (Kazanjian and Rao, 1999; Debruyne et al., 2002). For example, Meyer and Roberts (1986) have found product strategies to be key for the success of small technology-based firms. In addition, turbulent industries are characterized by substantial rates of product innovation, and firms that are not proactive in the product space tend to face serious difficulties in their struggle to survive. Meyer and Roberts (1986), Sorenson (2000) and Siggelkow (2003) among others, identify two main strategies that firms can implement in the product space: 1) versioning, a niche strategy that implies focusing on a particular sub-segment of the market, and taking continuous steps of incremental improvements of the same product; and 2) product portfolio broadening, an intra-industry product diversification strategy. Marketing scholars would label them as the vertical and the horizontal dimensions of a firm's product line.

Versioning is an important strategy for two main reasons. First, given the usually low entry barriers in turbulent industries, incumbents are often threatened in their core product niches by new entrants endowed with innovative products. By keeping its core products always updated and at the technological frontier, the firm can signal its intention and ability to disrupt the market periodically, implying that eventually a new breakthrough product will replace the actual standard (Smith et al., 1997). Competitors are forced to play continuous catch-up, and invest heavily to improve product quality.

Second, when consumer preferences are fragmented, versioning represents a way to segment customers without cannibalizing the existing product (Shapiro and Varian, 1998). For instance, early versions commanding high prices can be commercialized to costumers who quickly need 
the products, whereas later versions with decreasing prices are meant to attract a broader base of customers. Hence, we posit:

H1. In turbulent industries, startups that adopt a strategy of aggressive product versioning in a specific niche exhibit a higher survival rate.

Product portfolio broadening implies offering a large menu of products from different subsegments of the product space. Especially in highly dynamic industries, firms might signal an aggressive behavior by entering a large number of product niches. Moreover, product portfolio broadening could be used to raise entry barriers (Lancaster, 1990), an important strategic move when there are no initial sunk costs. By saturating the product space, the firm makes more difficult for de-novo competitors to enter in niches already populated.

Portfolio broadening might also help generate positive technological synergies that increase the overall quality of the firm's product offer. Indeed, when the rate of product obsolescence is high, the possibility to exploit economies of scale is limited. However, firms might try to exploit economies of scope by applying their technological capabilities to different niches.

Synergies might also come from the consumer side. Portfolio broadening could also be the necessary condition to pursue a bundling strategy. According to Gandal et al. (2002), product bundling leads to superior performance either when consumer preferences for different products are positively correlated, or if the main customers are organizations that average multiple agent preferences. Bakos and Brynjolfsson (1999) argue that bundling unrelated goods can be highly profitable since it becomes easier to predict consumers' valuations for a bundle of goods than their valuations when the goods are sold separately. Finally, bundling could be also used to extract rents from low quality products that are shadowed by high quality ones inside product packages (Kenney and Klein, 1983; Randall et al., 1998).

\section{H2. In turbulent industries, startups that adopt an aggressive strategy of product portfolio} broadening exhibit a higher survival rate. 
At this point, some interesting and unanswered questions naturally arise: How do the strategies of versioning and product portfolio broadening interact with each other? Are there synergies in pursuing both strategies at the same time? Or do the firms that focus on any of the two strategies end up enjoying a competitive advantage? Since startups are by definition small firms with limited resources and no organizational experience, the direction of their strategic orientation, i.e. a selected strategy vis-à-vis a mix of different strategies, should play a crucial role on the likelihood of survival.

To surmise the potential interaction between the two strategies, we resort to the literature on organizational learning, and more specifically to the concept of strategic learning (Kuwada, 1998; Thomas et al., 2001). Strategic learning aims to generate knowledge in support of future strategic initiatives that will, in turn, produce differences in organizational performances. Strategic learning becomes even more important for startups that have to create their organizational blueprints ex nihilo. Strategic learning, as well as organizational learning more in general, tends to increase through a continuous process of information accumulation. A critical component of this process is strategy repetition (Kuwada, 1998). Repetition is intended as the stable and frequent use of the same strategy. Since learning shows usually increasing returns phenomena (March, 1991), our underlining assumption is that learning returns diminish if firms disperse their "learning investments" along different strategy trajectories. To fix ideas, take two similar firms that invest the same amount $\mathrm{K}$ ( $\mathrm{K}$ could be any resource: Money, time, managers or researchers) in two possible strategies, A and B. The first firm puts all the efforts in only one strategy. The other invests a portion $\alpha(0<\alpha<1)$ in strategy A and a portion $(1-\alpha)$ in strategy B. Regardless of the direct outcomes of A and B, if the return from strategic learning (L) has the form $\mathrm{L}=\mathrm{f}(\mathrm{K})$ with $\mathrm{f}^{\prime}>0$ and $\mathrm{f}^{\prime}$ ' $>0$, where $\mathrm{f}$ is a function that expresses increasing returns, it could easily be that, under some reasonable conditions, $f_{A}(K)$ or $f_{B}(K)>f_{A}\left(\alpha^{*} K\right)+f_{B}\left[(1-\alpha)^{*} K\right]$ for every value of $\alpha$. 
The returns from strategic learning could be poor if a firm fragments its available resources, typically scarce for a startup, through a variety of strategic trajectories. In other words, an attempt to cover a wide range of market niches while deepening the firm's core product line might be detrimental for strategic learning opportunities, especially for highly resource constrained firms. Indeed, Pelham (1999) finds that generic strategic selection for small firms produces weaker competitive advantages, given the resource limitations of these organizations. Similarly, Covin and Slevin (1989) suggest that a clear definition of strategic postures produces the internal cohesiveness necessary to sustain the performance of small firms.

This line of reasoning leads to our last hypothesis:

H3. In turbulent industries, startups that focus on one type of strategy (either versioning or product portfolio broadening) exhibit a higher survival rate compared to those adopting a mixed strategy.

\section{INDUSTRY BACKGROUND, SAMPLE AND DATA}

\subsection{Industry Background}

The Security Software Industry (SSI) provides the test bed for our hypotheses. SSI is a recent niche of the software industry, a quintessential example of turbulent environments (Torrisi, 1998). ${ }^{2}$ SSI has experienced an unprecedented growth in recent years. The world market of SSI reached 4.4 billon dollars in 1999 from 3.2 billion dollars in 1998 and 2.2 billion dollars in 1997 (International Data Corporation, 1999).

The origins of the industry date back to the late 70 s, when the US government directed important investments in military projects linked to the security of data transmission. Large firms, like IBM and AT\&T, and academic research laboratories, especially at MIT and Stanford, worked actively on software security architectures, and developed and patented the major technological breakthroughs. Almost all basic patents have expired at the beginning of the 90s. At the end of the $80 \mathrm{~s}$, the rising market of home personal computers and the development of the 
Internet created a growing civilian demand, increasing the spectrum and the complexity of different products and services required.

Figure 1 shows the number of firms that entered and exited SSI and the observed hazard rates. This graph highlights the high industry turbulence, given the steady increase in the rates of entry and exit all over the period. In part this can be explained by the relatively small sunk costs needed to start a SSI venture; for example, the initial amount invested to set up Check Point, the fourth largest firm in SSI (1998), was only $\$ 300,000$.

\section{[FIGURE 1 ABOUT HERE]}

A distinctive feature of this industry is that the large firms, that were the first technology movers, were very slow to enter in the new civilian market and SSI became dominated by startups. Table 1 lists the most important world market leaders after ten years of life of SSI; it is worth noticing that no large incumbents appear in this list, and all market leaders are startups. By the year 2000 large incumbent firms, like IBM and HP, are just new entrants and insignificant players in this industry, which also legitimates our focus on startups.

\section{[TABLE 1 ABOUT HERE]}

To date, SSI includes a wide range of products: from the basic security software, such as Virtual Private Networks, Firewall and Virus Scanning to advanced security services like Public Key Infrastructures, Security Certification and Penetration Testing. Table 2 shows the major product niches in SSI according to a six digit SIC code classification.

\section{[TABLE 2 ABOUT HERE]}

The design of the general security protection of an information system is a complex project and it incorporates solutions of problems originated from different technological fields such as mathematics, software, hardware and network design. The technological core of the product is the "crypto algorithm", which specifies the mathematical transformations that are performed on data. A crypto algorithm is a procedure that takes the plain text data and transforms it into cipher text. The process could be reversed with a usual password. Speed of mathematical calculations and security level are the two main features on which SSI products are evaluated, because the time consumed by encrypting and decrypting processes depends on the length of 
mathematical algorithm and on the power of computing machines (Smith, 1999; Giarratana, 2004). The crypto algorithm is the principal object of a firm's patent under the technological patent class "cryptology". The main buyers of SSI products are large hardware and software producers, credit card makers and telecommunication companies.

\subsection{Sample Selection}

Our sample is composed by all firms that have introduced at least one product in SSI. Product introduction data were taken from Infotrac's General Business File ASAP and PROMT database that, from a large set of trade journals, magazines and other specialized press, reports several categories of "events" like product introductions, strategic alliances and licenses classified by industrial sectors. This database is the new version of the old Predicast database that has been used extensively in the literature. We searched for all press articles that reported a "Product announcement", a "New software release" and a "Software evaluation" in SSI (SIC Code 73726) from 1980 to 2000. Then, from each of these articles, we extracted the name of the company, the date of product introduction and the precise SIC code of the product (six digit SIC code). We found that the first product was introduced in 1989. We ended up with 411 different entrants in SSI. To control for firms' group structure we used information from the Business and Company Resource Center database, Gale Group's Infotrac. We have constructed "super firms"' which correspond to the end-of-period actual entities. Hence, for example, if any two sample firms merged during the sample period, we consider them merged from the start (see for this procedure, Klepper, 2002). Specifically, in SSI there have been 79 mergers among startups. In order to moderate the classical censoring problem of survival analyses, we preferred to restrict our sample to the firms that entered from 1989 to 1998; this selection eliminates too young entrants - the 1999 and 2000 cohorts - reducing censoring issues. As a matter of fact, our conservative procedure allows us to track the existence and the product strategies of the 1989-98 entrants in the two years following the end of our sample period (1998). This criterion gives us a sample of 270 firms that entered in SSI from 1989 to 1998. 
By checking firms' histories from different sources, we found that these 270 entrants are all start-ups in SSI. This confirms that SSI is mainly dominated by start-ups and incumbents are latecomers and play a marginal role. The 270 start-ups have introduced 1,125 different products. All the products were classified in 6 different niches (see Table 2). We also cleaned for eventual product double-counting (i.e. articles that cite the same event).

\subsection{Econometric Models}

A wide collection of empirical works provides a standard econometric approach to deal with survival (Geroski, 1995; Audretsch, 1991; Klepper, 2002). Logit models for selection and duration models for survival are the most common techniques employed in the literature. A logit specification assumes that the probability to exit is influenced by a series of covariates. Usually, the dependent variable takes the value 1 if the firm is exited, and 0 otherwise. Duration models were initially imported from biology to analyze individual jumps in and out unemployment cohorts (see Wooldrigde, 2002). These models are based on hazard functions, i.e. distribution functions of the duration or spell length for an individual, $F(t)=\operatorname{Pr}(T<t)$, where $T$ is the duration, and are used to estimate the rates at which spells are completed at duration $\mathrm{t}$, given that they have lasted until t. Even if the empirical literature offers a variety of parametric duration models such as exponential and Weibull, the proportional hazard models (Cox specification) are better suited when hazard rates change with the duration, showing period of hazard acceleration and deceleration (Kiefer, 1988).

\subsection{Dependent Variables}

Exit. This is a dummy variable that takes the value of 1 if the firm has exited the industry by the year 2000 and 0 otherwise. We triangulated different databases to obtain this information. Precisely, we checked for the firm's existence by the year 2000: i) in the US (www.uspto.gov) and European (oami.eu.int) Trademark Databases looking for firms" "live" software trademarks 
after 12/31/1998; ${ }^{3}$ ii) in some financial databases - Hoover's (www.hoovers.com), Mergent on Line (www.mergentonline.com), Bureau Van Djik's Orbis (www.bvdep.com) - for any firm's balance sheet after the financial year 1998; iii) in Infotrac Company Resource Data Center and in Infotrac PROMT for any press article that included news of firms after 1998. This is our dependent variable in the logit specifications.

Duration. The length of time that elapses from entry either until exit or until 2000. Since we do not have the precise date of exit of the firm, we introduced a simple criterion to track firms' exit date (see for this procedure Breschi et al., 2003). Exit date was assigned if a firm did not release any new version of an existing product or a brand new product for two years. There are no cases in the data of firms that after a period of more than two years of inactivity released again new products in SSI. There is still a censoring problem for all firms that are active by the year 2000, whose exit might take place somewhere in the future. This is our dependent variable in the Cox specifications.

\section{$\underline{3.5 \text { Predictor Variables }}$}

Versioning. This variable (Versioning) counts the average annual number of new versions of the product that spurt firm's entry in SSI either during the firm's lifetime or till 2000. This means that if CheckPoint entered in SSI in 1994 introducing a Firewall and exited in 2000, we computed how many new versions of this product CheckPoint has released till 2000 and divided it by the number of surviving years (number of products in the entry niche/firm's life span). Firm's entry product niche is particularly important for startups because it usually creates a strong reputation effect and sustains the competitive advantage in the preliminary phases of competition (Kazanjian and Rao, 1999). Moreover, niche specialization strategy is usually pursued in the niche that characterized entry (Debruyne et al., 2002). At the same time, our direct interviews with some startups' managers confirm the importance of building up the firm's reputation around the product that has spurt entry (see also Giarratana, 2004).

Product portfolio broadening. We proxy this variable with two different measures. The first (Portfolio) counts the average annual number of products the firm has released in niches 
different from its entry niche either during the firm's lifetime or till 2000. As before, we divided the number of products by the firm's time of permanence on the market. The second (Herfindahl) is the Herfindahl index of the firm's product portfolio at the end of the sample period. By construction, this measure varies between 0 and 1 , and decreases the larger is the degree of intra-industry diversification.

Mixed strategy. Our aim is to test if the strategies of versioning and product portfolio broadening show any interaction with each other. Empirically we can address this issue simply by constructing a new covariate equal to the product (Mixed=Versioning*Portfolio) of the versioning and product portfolio variables. ${ }^{4}$

\subsection{Control Variables}

First mover advantages. A large body of the literature has analyzed and measured the magnitude and sustainability of first-mover and early-mover advantages (Lieberman and Montgomery, 1988, 1998; Mitchell, 1991). In SSI, where entry and exit barriers are low, and scale economies are less important, the sustainability paradigm of the first-mover advantage is under the most severe test (Gandal, 2001; Lieberman, 2003). Nonetheless, early movers in SSI might benefit from the existence of the same users' switching costs that characterize the software industry as a whole (Torrisi, 1998). Users who want to move to a different software provider might need to learn how the new supplier's product works, an investment that is already sunk with the software product in use. Early-movers might also benefit from a reputation effect. Established firms that offer a solution that works have an advantage over new competitors whose product offer is characterized by higher uncertainty. In some niches of SSI, for instance antivirus, not only it is important to offer a high quality product, suppliers might have also to convince prospective buyers that they will be able to update their products in the incoming future. Established firms with a built reputation might be more trustworthy. To test for the presence of first-mover advantages we follow the standard approach in the literature (see, for instance, Klepper, 2002) and create two cohort dummies (Cohort1 and Cohort2). Since we have a total of 10 years of industry life, Cohort 1 and Cohort 2 take the value 1 if a startup has 
entered in the period 1989-1991 (the first 3 years) and in the period 1992-1994 (the second three years) respectively, and 0 otherwise.

Technological capabilities. In turbulent environments firms endowed with "dynamic capabilities", i.e. firms able to continuously achieve new forms of competitive advantage, have an edge over competitors in the fight to survive (Teece et al., 1997). In SSI, due to its sciencebased nature, one of the leading dynamic capabilities is technological soundness. A deep technological background and innovative capability is therefore a necessary condition to shortterm survival and long-run performance. We use a dummy variable (Technology) that takes the value of 1 if the startup was a technological supplier in a license agreement or if it was granted a patent at the US Patent Office. Patent data were downloaded from the US Patent Office web site. We considered all the patents granted in the US class 380 (Cryptography). Information about licenses was drawn from the same database used for product introduction. We downloaded all the "licensing contracts" classified under the Security Software Sector. We also added to each firm the active (Seller) or passive (Buyer) role in the contract, by extracting the information from the article text.

Though "Technology" could be subject to some endogeneity criticisms, since firms surviving longer have more chances to supply technology or file a patent, it is worth noticing that $54 \%$ of the sample firms were granted a patent and $41 \%$ had signed a license contract before they actually entered the market with a product. This provides good evidence that our variable measures an initial capability. As a matter of fact, given the good functioning of the market for technology in SSI, firms can easily obtain revenues by licensing their crypto algorithms. Indeed, in $1998,14.9 \%$ of total sales of the 15 market leaders came from licensing algorithm contracts.

Partnering. This variable (Alliance) counts the annual average number of alliances that a firm signed during its life span. Information about alliances was again drawn from Infotract PROMT and ASAP. We downloaded all the "strategic alliances" and "joint ventures" classified under the Security Software Sector. We have included all strategic alliances in research and development, marketing and distribution that do not involve an active role as technology supplier by the startup. 
We add the partnering control following the recent literature on startups that has stressed the importance of active partnering for usually resource constrained firms. Partnering can be used to shorten product development time by quickly learning complementary technological competencies and exploiting research synergies (Miotti and Sachwald, 2003). Alliances, especially with big partners, could be an optimal vehicle to share costs, improve market penetration and diminish risks among startups (Gans and Stern, 2003). Finally, partnering can be a means to penetrate market niches that are outside the startup's core activity. For example, Sakakibara (1997) argues that competence complementarities between partners foster the alliance's success. By leveraging the experience, reputation and knowledge of other firms already active in the new niche, the company can improve market penetration and reduce the risk of failure. Partnering can therefore be a strategy for broadening the startup's product offer. Industry conditions. We control for average revenues in the industry at the time of entry. The variable (Industry) is time varying and it is constructed dividing the total revenues generated in SSI in a given year by the number of active firms in that year. Total SSI revenues generated by year are taken from Hoover's (www.hoovers.com).

US startup. This is a dummy variable that takes the value of 1 if the startup is a US firm, and 0 otherwise.

Niches. We control for systematic differences across entry niches through a set of dummy variables.

Table 3 describes the variables used as covariates, and table 4 reports means, standard deviations and correlations.

[TABLE 3 AND 4 ABOUT HERE]

\section{RESULTS}

Table 5 reports the results of the logit estimations. Model 1 includes "Portfolio" as a proxy for product portfolio broadening, whereas model 2 uses our variable "Herfindahl".

[TABLE 5 ABOUT HERE] 
Our hypotheses gain support from the data since firms that introduce a higher annual average number of versions of their original product or a higher annual average number of products belonging to different market niches command a much higher probability to survive. Note that we obtain similar results using either "Portfolio" or "Herfindahl". To check the robustness of these latter findings, we have experimented with alternative measures of versioning and product portfolio broadening. For instance, we have used two dummies that took the value of 1 if the startup introduced at least a new version and at least a product in a different niche, respectively, in its first year of activity. We also measured the time that elapsed from entry till a new version was released or till entry in a new niche occurred, respectively, adjusted by the duration of the startup's presence in SSI. All these different specifications lead to similar qualitative results.

The interaction covariate "Mixed" has a significant and negative impact on the survival probability. This finding suggests that for startups with usually scarce resources, focusing on one type of strategy (versioning or product portfolio broadening) commands a higher probability of surviving than adopting a mixed strategy. Hence, a firm that is "stuck in the middle" has a lower chance to survive than focused rivals because the hazard of exit increases if firms shift from a focused strategy to a mixed one. Indeed, the opportunities of accumulating strategic learning are reduced if a firm with scarce resources disperses its learning investments across different strategy trajectories (Kuwada, 1998). To better quantify this finding, consider the following experiment: a startup can choose between a mixed strategy in which it reaches half of the observed maximum (see Table 4.a) in versioning (Versioning=2.18) and product portfolio broadening (Portfolio=3), and a focused strategy in which it obtains the observed maximum (Portfolio=6 and Versioning=4.37) in either "Portfolio" or "Versioning" and the minimum (Portfolio=0.07 and Versioning=0.14) in the other dimension. A focused strategy decreases the hazard of exit between $39 \%$ and $42 \%$ depending on the strategy chosen. This suggests two possible routes for startups' survival in SSI: a) a niche product leadership, i.e. specializing with an aggressive versioning in a particular niche and keeping the product at the technological frontier; b) the one-stop shop strategy, i.e. offering a complete security package to 
the customers, which includes also consultancy services. It is worth noting that about a third of the revenues of the top 15 startups in SSI comes from consultancy services.

In order to check for the relevance of post-entry product strategies, we perform a LR test comparing the two models with a more spare specification that uses only control variables. At the 5\% significance level, the LR test suggests that "Versioning", "Portfolio" and "Mixed" should not be dropped (the values of the statistics are 44.94 and 38.16 respectively).

As far as it concerns our control variables, our dummy for early industry entrants (Cohort1) is not significant at all, suggesting that firms that have entered SSI in its early days do not show a higher probability to survive. This result seems quite robust. Indeed, we have experimented with different time windows for early entrants and with a time trend ( = 1999 - year of startup's entry), obtaining always insignificant coefficients. After all, it is not surprising that first-mover advantages are not important in this industry. First-mover advantages tend to be typically associated with shake-out industries where early entrants end up enjoying larger scale and learning economies, and benefiting from network and reputation effects. Indeed, only weak evidence of first-mover advantages has shown up in the really few studies focused on turbulent industries (Makadok, 1998; Gandal, 2001; Lieberman, 2003). In SSI, first-mover advantages are less likely to matter because the industry is characterized by strong product-based competition centered on the "quality" of the technology. In fact, most of the product demand is driven by large ICT incumbents who represent high-skilled selective customers with low switching costs among different programs. Moreover, important patents on basic knowledge, granted in the late 1970s, have already expired.

As expected, technological capabilities play an important role in shaping startups' probability of survival. If all other variables are held at their mean values, entrants endowed with technological capabilities are $16.9 \%$ more likely to survive than entrants without such capabilities (using estimates from model 1).

Startups that engage in active partnering do not seem to be more likely to survive. At its face value, this finding would imply that strategic alliances help very little startups in increasing survival probability. There are several plausible explanations for this result. The most obvious is 
that strategic alliances might be instrumental to achieve strategies of versioning and product portfolio broadening. To prove this conjecture, we perform a test for mediation according to the procedure in Baron and Kenney (1986). Mediation is a hypothesized causal link in which one variable affects a second variable that, in turn, affects a third variable. In so doing, we perform other two regressions with the same controls. First, we see that "Portfolio" and "Versioning" remain significant and with the expected sign if we drop "Alliance" from the logistic regression in Table 6. Then, we employ as dependent variables of a standard OLS regression "Portfolio" and "Versioning", and as predictors, all our controls plus "Alliance" (see Appendix). "Alliance" appears to be significant at $5 \%$ level in both regressions and with a positive sign. Using these estimates, we perform the Sobel (1982) and the Goodman (1960) tests (see Table 6), which confirm that our data are consistent with a mediation model in which alliances are instruments to pursue product strategies.

The estimates obtained from the duration models (Cox specification) can be found in Table 7 . Results are overall consistent with the logit estimations. At a given time $t$, firms endowed with technological capabilities and that are engaged in focused strategies of versioning and portfolio broadening command a higher probability to last longer. There is no significant benefit of being a first mover in the industry, nor of being very active in partnering with other firms.

[TABLE 6 AND TABLE 7 ABOUT HERE]

\section{CONCLUSIONS AND DISCUSSION}

In this paper we have empirically investigated the determinants of startups' survival in the Security Software Industry, a prototypical example of a turbulent industry. Our findings suggest that post-entry strategies of versioning and product portfolio broadening are important in explaining the survival of the new ventures even after controlling for initial entry conditions. The analysis of post-entry product strategies beyond traditional determinants of startups' survival constitutes our contribution to the existing literature. Moreover, our results seem to confirm that coherence and focus in post-entry strategies command a higher rate of survival. These findings, in addition to being interesting per se, are most valuable given the scarce 
empirical literature on startups' survival in turbulent industries and their post-entry strategies. At this regard, our work constitutes an attempt to bridge the gap between the standard industrial organization studies on firms' survival (see Klepper, 2002) and the tradition that more directly refers to population ecology studies (see Dobrev et al., 2001).

As secondary findings, we show that in turbulent industries, like SSI, first mover advantages are not significant, whereas we confirm the important role played by technological capabilities. We think that this evidence is driven by the particular characteristics of turbulent industries, that is, industries with low entry barriers and scarce scale economies, but with a fierce competition on technology-based products. Finally, partnering intensity does not seem to have a direct effect on the survival of new entities, although we show that alliances might be instrumental for pursuing product strategies.

Our findings have several implications for practitioners. As far as it concerns pre-entry initial conditions, without reliable first mover advantages, in turbulent environments initial capabilities remain pivotal to guarantee survival in the early stages of the firm's life. This means that "high quality" entrants do not find it difficult to compete also in later stages of industry evolution, and that entry barriers are more on the product-quality side. Indeed, it is difficult to observe "lockin" effects and firms' technological capabilities are exposed to a higher degree of selection. Taking this argument a step further, one could conjecture that when entrants are deprived of an important strategic tool as the time of entry, the embedded capabilities of startups are even more important. The only true lock-in effect seems to come from the selection of the firm's strategy. Strategic learning has been shown to be very important for firms in general, and particularly for startup organizations with scarce resources. The dispersion of the firm's resources along a variety of different strategies could decrease the returns from strategic learning and undermine the firm's performance and stability (Kuwada, 1998).

In short, the recipe for startups' survival is a fine mix of pre-entry technological capabilities and stable post-entry product strategies. Other initial conditions strictly linked with scale economies like entry time have a limited importance. Further research attempting to reproduce these findings on similar industries (like laser, biotech, etc.) could strengthen these conjectures. At this regard, it is not trivial to stress that these trajectories to survival seem to be critical in industries where incumbent diversified firms find difficult to compete, while specialized startups dominate. 
Finally, we are well aware that this work shows some limitations. From a theoretical point of view, we have used the distinction between shake-out industry and turbulent industries to sharpen our discussion of the differences in strategic conduct between the two. First, the use of a polar characterization is not meant to deny the existence of a variety of "hybrid" cases. Second, and most important, we rarely can count on the whole history of an industry from birth to death. So, we have no guarantee that a turbulent industry will no exhibit some shake-out in the future. Our conjecture, that we cannot prove, is that turbulent industries are structurally different from traditional shake-out industries, and this makes the shake-out unlikely. However, even if a shake-out might occur this would not diminish the empirical relevance of our study. Our results should then be interpreted in terms of the drivers of survival in the initial phases of the industry life cycle in which the competitive dynamics are quite different from those in later phases. After all, according to the literature (Klepper, 2002), firms that dominate the industry in the long run are those that entered and survived the first turbulent phase. From an econometric point of view, problems of endogeneity and measurement are present: for instance, technological capabilities and post-entry strategies could indeed be proxies of the same unobserved entrepreneurs' ability. As a matter of fact, the two product strategies could depict two different "initial" blueprints (Baron and Hannan, 2002): i) a product-oriented startup that bases its competitive advantages on the technological quality of one product; ii) a serviceoriented start-up that uses the intra-industry product diversification to build up a complete offer. Indeed, this confirms that direct, extensive surveys to startups could give information that with great difficulty could be extracted from the raw data. We are confident that these shortcomings could be addressed in future research. 


\section{End Notes}

${ }^{1}$ Incumbents are defined as firms already competing in a sector outside the industry under scrutiny.

${ }^{2}$ This section draws upon Giarratana (2004) to which we refer for further details on the history and evolution of SSI.

${ }^{3}$ Trademarks granted are withdrawn if the firm is not actually using them in the market. As a matter of fact, since US and Europe represent the two most important markets for software products, firms that want to operate in these markets should own at least a "live" trademark there, regardless of their country origins.

${ }^{4}$ The product between the versioning variable and our second measure of product portfolio (Herfindahl) could not be used given the too high correlation with the versioning variable. The correlation biases the effect of the interaction term.

\section{References}

Abernathy, W.J., J. Utterback. 1978. Patterns of industrial innovation. Technology Review. 80(2) 41-47.

Audretsch, D. 1991. New-firm survival and the technological regime. Review of Economics and Statistics. 73(3) 441-450.

Bakos, Y., E. Brynjolfsson. 1999. Bundling information goods: Pricing, profits and efficiency. Management Science. 45(12) 1613-1630.

Barnett, W.P., J.H Freeman. 2001. Too much of a good thing? Product proliferation and organization failure. Organization Science. 12(3) 539-558

Baron, J.N., M.T. Hanna. 2002. Organizational blueprints for success in high-tech startups. California Management Review. 44(3) 8-36

Baron, R. M., D.A. Kenny. 1986. The moderator-mediator variable distinction in social psychological research: Conceptual, strategic, and statistical considerations. Journal of Personality and Social Psychology. 51(3) 1173-1182.

Bhide, A. 2000. The Origin and Evolution of New Businesses: Oxford University Press.

Breschi, S., F. Lissoni, F. Malerba. 2003. Knowledge-relatedness in firm technological diversification. Research Policy. 32(1) 69-87

Carroll, G., E. Masakowski. 1987. The career dynamics of self-employment. Administrative Science Quarterly. 32 570-589.

Chesbrough, H. 2000. Designing corporate ventures in the shadow of private venture capital. California Management Review. 42(3) 31-49.

Covin, J.G., D.P. Slevin. 1989. Strategic management of small firms in hostile and benign environments. Strategic Management Journal. 10(1) 75-87. 
D’Aveni, R. 1994. Hypercompetition: Managing the Dynamics of Strategic Maneuvering: New York Free Press.

Debruyne, M., R. Moenaert, A. Griffin, S. Hart, E. Hultink, H. Robben. 2002. The impact of new product launch strategies on competitive reaction in industrial markets. Journal of Product Innovation Management. 19(2) 159-170.

Dobrev, S.D., T.Y. Kim, M.T. Hannan. 2001. Dynamics of niche width and resource partitioning. American Journal of Sociology. 106(4) 1299-1337

Gandal, N. 2001. The dynamics of competition in the internet search engine market. International Journal of Industrial Organization. 19 (7) 1103-1117.

Gandal, N., S. Markovich, M. Riordan. 2002. Ain't it "suite"? Strategic bundling in the PC office software market. Unpublished manuscript.

Gans, J.S., S. Stern. 2003. The product market and the market for "Ideas": Commercialization strategies for technology entrepreneurs. Research Policy. 32(2) 333-350.

Geroski, P. 1995. What do we know about entry? International Journal of Industrial Organization. 13(4) 421-440.

Giarratana, M.S. 2004. The birth of a new industry: entry by startups and the drivers of firm growth. The case of encryption software. Research Policy. 33(5) 787-806.

Goodman, L.A. 1960. On the exact variance of products. Journal of the American Statistical Association. 55(2) 708-713.

Hall, W.K. 1980. Survival strategies in a hostile environment. Harvard Business Review. 58(5) 7585.

Henderson, R., K. Clark. 1990. Architectural innovation: the reconfiguration of existing product technologies and the failure of established firms. Administrative Science Quarterly. 35(1) 930.

Ilinitch, A., R. D’Aveni, A. Lewin. 1996. New organizational forms and strategies for managing in hypercompetitive environments. Organization Science. 7(3) 211-220.

Kazanjian, R., H. Rao. 1999. The creation of capabilities in new ventures: A longitudinal study. Organization Studies. 20(1) 125-137.

Kenney, R.W., B. Klein. 1983. The economics of blocking booking. Journal of Law \& Economics. 26(3) 497-540

Klepper, S. 2002. Firm survival and the evolution of oligopoly. Rand Journal of Economics. 33(1) 37-61.

Kuwada, K. 1998. Strategic learning: The continuous side of discontinuous strategic change. Organization Science. 9(6) 719-736.

Lampel, J., J. Shamsie. 2003. Capabilities in motion: New organizational forms and the reshaping of the Hollywood movie industry. Journal of Management Studies. 40(8) 2189-2210

Lancaster, K. 1990. The economics of product variety. Marketing Science. 9(3) 189-211. 
Lieberman, M. 2003. Did first-mover advantage survive the Dot-com crash? Unpublished manuscript. Anderson Graduate School of Management.

Lieberman, M., D. Montgomery. 1988. First-mover advantages. Strategic Management Journal. 9 $41-58$.

Lieberman, M., D. Montgomery. 1998. First-mover (Dis)advantages: Retrospective and link with the resource-based view. Strategic Management Journal. 19(12) 1111-1125.

Makadok, R. 1998. Can first-mover and early-mover advantages be sustained in an industry with low barriers to entry/imitation? Strategic Management Journal. 19(7) 683-696.

March, J.G. 1991. Exploration and exploitation in organizational learning. Organization Science. 2(1) $71-87$.

Mata, J., J.A.F. Machado. 1996. Finn startup size: A conditional quintile approach. European Economic Review. 40(6) 1305-1323.

McKendrick, D.G., J. Jaffee, G.R. Carroll, O.M. Khessina. 2003. In the bud? Analysis of disk array producers as a (possibly) emergent organizational form. Administrative Science Quarterly. 48(1) 348-381.

Meyer, M.H., E.B. Roberts. 1986. New product strategy in small technology-based firms: A pilot study. Management Science. 32(7) 806-821.

Miotti, L., F. Sachwald. 2003. Co-operative R\&D: Why and with whom? An integrated framework of analysis. Research Policy. 32(8) 1481-1499.

Mitchell, W. 1991. Dual clocks: Entry order influences on incumbents' and newcomer market share and survival when specialized assets retain their value. Strategic Management Journal. 12(2) 85-100.

Nalebuff, B. 2004. Bundling as an entry barrier. Quarterly Journal of Economics. 119(1) 159-87.

Pelham, A.M. 1999. Influence of environment, strategy and market orientation on performance in small manufacturing firms. Journal of Business Research. 45(1) 33-46.

Randall, T., K. Ulrich, D. Reibestein. 1998. Brand equity and vertical product line extent. Marketing Science. 17 (4) 356-370.

Roberts, E.B. 1991. High stakes for high-tech entrepreneurs: Understanding venture capital decision making. Sloan Management Review. 32(2) 9-20.

Sakakibara, M. 1997. Heterogeneity of firm capabilities and cooperative research and development: An empirical examination of motives. Strategic Management Journal. 18(4) 143-164.

Schmalensee, R. 2000. Antitrust issues in Schumpeterian industries. American Economic Review. 90(2): 192-197.

Schumpeter, J. A. 1934. The Theory of Economic Development: Harvard University Press.

Shane, S. 2001. Technological regimes and new firm formation. Management Science. 47(9) 11731190. 
Shapiro, C., H.R. Varian. 1998. Versioning: the smart way to sell information. Harvard Business Review. 76(6) 106-107.

Siggelkow, N. 2003. Why focus? A study of intra-industry effects. Journal of Industrial Economic. 51(2) 121-148.

Smith, K., G. Grimm, G. Young, S. Wally. 1997. Strategic groups and rivalrous firm behavior: Towards a reconciliation. Strategic Management Journal. 18(2) 149-157.

Smith, R. 1999. Internet Cryptography. Addison-Wesley, Reading USA.

Sobel, M. E. 1982. Asymptotic intervals for indirect effects in structural equations models. In S. Leinhart (Ed.), Sociological methodology, San Francisco: Jossey-Bass 290-312.

Sorenson, O. 2000. Letting the market work for you: An evolutionary perspective on product strategy. Strategic Management Journal. 21(2) 277-292

Stern, I., A.D. Henderson. 2004. Within-business diversification in technology-intensive industries. Strategic Management Journal. 25(5) 487-505.

Teece, D.J, G. Pisano, S. Shuen. 1997. Dynamic capabilities and strategic management. Strategic Management Journal. 18(7) 509-33.

Thomas, J.B., S.W. Sussman, J.C. Henderson. 2001. Understanding "strategic learning": Linking organizational learning, knowledge management, and sensemaking. Organization Science. 12(3) $331-345$

Thomas, L.G. 1996. The two faces of competition: Dynamic resourcefulness and the hypercompetitive shift. Organization Science. 7(3) 221-242

Torrisi, S. 1998. Industrial Organisation and Innovation: an International Study of the Software Industry: Edward Elgar Cheltenham, UK

Tripsas, M., G. Gavetti. 2000. Capabilities, cognition, and inertia: Evidence from digital imaging. Strategic Management Journal. 21(10) 1147-1161

Tushman, M.L., P. Anderson. 1986. Technological discontinuities and organizational environments. Administrative Science Quarterly. 31(3) 439-465

Wagner, J. 1994. The post-entry performance of new small firms in German manufacturing industries. Journal of Industrial Economics. 42(2) 141-154.

Winter, S. 1984. Schumpterian competition in alternative technological regimes. Journal of Economic Behavior and Organization. 4(3) 287-320.

Wooldridge, J. 2002. Econometric Analysis of Cross Section and Panel Data. MIT Press. 
Tables and Figures

Table 1: World market leaders in SSI, 1998

\begin{tabular}{|c|c|c|c|c|c|}
\hline Rank & Firm & $\begin{array}{r}\text { Revenues } \\
(\$ \mathrm{ml})\end{array}$ & $\begin{array}{r}\text { Net Income } \\
(\$ \mathrm{ml})\end{array}$ & $\begin{array}{r}\text { World } \\
\text { market share }\end{array}$ & $\begin{array}{r}\text { Entry } \\
\text { Year }\end{array}$ \\
\hline 1 & Network Ass. & 990 & 36.4 & 0.171 & 1993 \\
\hline 2 & Symantec & 578.4 & 85.1 & 0.099 & 1990 \\
\hline 3 & RSA Data Security & 171.3 & 29.4 & 0.029 & 1991 \\
\hline 4 & Check Point & 141.9 & 69.9 & 0.024 & 1995 \\
\hline 5 & Rainbow Technology & 109.2 & 2.5 & 0.018 & 1998 \\
\hline 6 & Axent Technology & 101 & 7.7 & 0.017 & 1994 \\
\hline 7 & Trend Micro Devices & 86.2 & 3.6 & 0.014 & 1991 \\
\hline 8 & Secure Computing & 61.4 & -3.3 & 0.010 & 1994 \\
\hline 9 & Entrust Techologies & 49 & -23.8 & 0.008 & 1997 \\
\hline 10 & Cylink & 42.8 & 5.1 & 0.007 & 1995 \\
\hline 11 & SystemSoft & 42.6 & -19.7 & 0.007 & 1998 \\
\hline 12 & VeriSign & 38.9 & -19.7 & 0.006 & 1998 \\
\hline 13 & BindView & 38.5 & 3.3 & 0.006 & 1995 \\
\hline 14 & Aladdin & 36.1 & 0.7 & 0.006 & 1997 \\
\hline 15 & Safenet & 23.2 & -2.4 & 0.005 & 1998 \\
\hline Total & & 2487.3 & 174.8 & 0.429 & \\
\hline
\end{tabular}

Source: Hoover's and Infotrac, see Giarratana (2004)

Table 2: Product niches in SSI

\begin{tabular}{|l|l|}
\hline Niche & Description \\
\hline $\begin{array}{l}\text { Authentication-Digital } \\
\text { Signature }\end{array}$ & $\begin{array}{l}\text { Products for the authentication of digital documents with a } \\
\text { copyrighted mark }\end{array}$ \\
\hline \begin{tabular}{l} 
Antivirus \\
\hline $\begin{array}{l}\text { Data and Hardware } \\
\text { Protection }\end{array}$
\end{tabular} & $\begin{array}{l}\text { Programs that detect and clean viruses from computers } \\
\text { stored in hard drivers }\end{array}$ \\
\hline Firewalls & A sort of checking door between different networks \\
\hline Utility Software & $\begin{array}{l}\text { Utility software programs that assure the protection and } \\
\text { proper execution of the operating system and applications, } \\
\text { giving the possibility to recreate the content of some data } \\
\text { packages lost }\end{array}$ \\
\hline $\begin{array}{l}\text { Network Security and } \\
\text { Management }\end{array}$ & $\begin{array}{l}\text { Network security management packages that guarantee the } \\
\text { high performing functioning of different networks }\end{array}$ \\
\hline \multicolumn{2}{|l|}{ Source: Our elaboration from Infotrac according to a six digit SIC code classification } \\
\hline
\end{tabular}


Table 3: Covariates' description.

\begin{tabular}{|l|l|}
\hline Label & Description \\
\hline Versioning & $\begin{array}{l}\text { Firm } i \text { 's number of products released in the niche that corresponds to the } \\
\text { firm's entry niche, standardized by the time of market permanence of firm } i\end{array}$ \\
\hline Portfolio & $\begin{array}{l}\text { Firm } i \text { 's number of products released in all the niches different from the niche } \\
\text { that corresponds to the firm's entry niche, standardized by the time of market } \\
\text { permanence of firm } i\end{array}$ \\
\hline Mixed & The product of the variables "Portfolio" and "Versioning" \\
\hline Herfindahl & $\begin{array}{l}\text { Herfindahl index calculated on firm } i \text { 's product portfolio at the end of the } \\
\text { period }\end{array}$ \\
\hline Cohort1 & Dummy for firms entered in the first cohort 1989-1991 \\
\hline Cohort2 & Dummy for firms entered in the second cohort 1992-1994 \\
\hline Technology & $\begin{array}{l}\text { Dummy for firms that were granted a patent or signed a license as a } \\
\text { technology supplier (technology seller) }\end{array}$ \\
\hline Alliance & $\begin{array}{l}\text { Number alliances signed by firm } i \text {, standardized by the time of market } \\
\text { permanence of firm } i\end{array}$ \\
\hline Industry & $\begin{array}{l}\text { Ratio between total SSI revenues at time "t" (million dollars) and the number } \\
\text { of active firms at time " } t \text { ". }\end{array}$ \\
\hline US startup & Dummy for US firms \\
\hline
\end{tabular}

Table 4: Descriptive statistics and correlations of covariates

\begin{tabular}{|l|r|r|r|r|ccccccccc|}
\multicolumn{1}{c|}{} & \multicolumn{1}{c|}{ Mean } & \multicolumn{1}{c}{ S. D. } & \multicolumn{1}{c}{ Min } & Max & \multicolumn{1}{c}{1.} & 2. & 3. & 4. & 5. & 6. & 7. & 8. & 9. \\
\hline 1. Versioning & 0.432 & 0.394 & 0.143 & 4.38 & 1.00 & & & & & & & & \\
2. Portfolio & 0.280 & 0.560 & 0.071 & 6 & 0.19 & 1.00 & & & & & & & \\
3. Herfindahl & 0.895 & 0.205 & 0.193 & 1 & -0.15 & -0.51 & 1.00 & & & & & & \\
4. Cohort1 & 0.207 & 0.406 & 0 & 1 & -0.24 & 0.07 & -0.13 & 1.00 & & & & & \\
5. Cohort2 & 0.578 & 0.495 & 0 & 1 & 0.14 & -0.05 & 0.11 & -0.60 & 1.00 & & & & \\
6. Alliance & 0.119 & 0.324 & 0 & 1 & 0.29 & 0.38 & -0.25 & -0.10 & -0.04 & 1.00 & & & \\
7. Technology & 0.581 & 1.451 & 0 & 14.5 & 0.21 & 0.46 & -0.48 & 0.07 & -0.06 & 0.45 & 1.00 & & \\
8. Industry & 673 & 364 & 0 & 1078 & 0.19 & -0.05 & 0.13 & -0.69 & 0.14 & 0.13 & -0.07 & 1.00 & \\
9. US startup & 0.744 & 0.437 & 0 & 1 & 0.03 & 0.05 & -0.08 & 0.07 & 0.01 & 0.13 & 0.00 & -0.12 & 1.00 \\
\hline
\end{tabular}


Table 5: Results from logit estimation (exit probability-entrants from 1989 to 1998)

\begin{tabular}{|l|r|r|r|r|}
\cline { 2 - 5 } \multicolumn{1}{c|}{} & \multicolumn{2}{c|}{ Model 1 } & \multicolumn{2}{c|}{ Model 2 } \\
\cline { 2 - 5 } \multicolumn{1}{c|}{} & Coef. & Std. Err. & Coef. & Std. Err. \\
\hline Versioning & $-2.74^{* *}$ & 0.55 & - & - \\
Mixtfolio & $-7.99^{* *}$ & 2.70 & $-2.09^{* *}$ & 0.91 \\
Herfindahl & $3.78^{* *}$ & 1.43 & $1.69^{*}$ & 1.05 \\
\hline Cohort1 & - & - & $2.62^{* *}$ & 1.30 \\
Cohort2 & 0.24 & 0.93 & 1.51 & 1.72 \\
Technology & 0.40 & 1.66 & 0.41 & 0.87 \\
Alliance & $-2.02^{* *}$ & 0.91 & $-1.97 * *$ & 0.84 \\
Industry & 0.30 & 0.17 & 0.13 & 0.11 \\
US startup & -0.03 & 0.03 & -0.01 & 0.02 \\
Constant & 0.07 & 0.64 & 0.16 & 6.61 \\
\hline Dummy variables & $9.84^{* *}$ & 3.42 & 3.66 & 3.62 \\
for product niches & \multicolumn{2}{|c|}{ YES } & \multicolumn{2}{|c|}{ YES } \\
\hline Observations & \multicolumn{2}{|c|}{270} \\
\hline LogLik. & \multicolumn{2}{|c|}{270} & \multicolumn{3}{c|}{-41.64} \\
\hline
\end{tabular}

Note: * and $* *$ mean 0.10 and 0.05 level of significance, respectively

Table 6: Results of the Sobel and Goodman tests for mediation

\begin{tabular}{|c|c|c|}
\cline { 2 - 3 } \multicolumn{1}{c|}{} & Portfolio & Product \\
\hline Sobel test & $2.41^{* *}$ & $2.57 * *$ \\
\hline Goodman test & $2.36 * *$ & $2.52^{* *}$ \\
\hline
\end{tabular}

Note: * and ** mean 0.10 and 0.05 level of significance, respectively 
Table 7: Results for Cox proportional Hazard model (Hazard of exit- entrants from 1989 to 1998)

\begin{tabular}{|c|c|c|c|c|}
\hline & \multicolumn{2}{|c|}{ Model 1} & \multicolumn{2}{|c|}{ Model 2} \\
\hline & Coef. & Std. Err. & Coef. & Std. Err. \\
\hline Versioning & $-2.05^{* *}$ & 0.33 & - & \\
\hline Portfolio & $-4.46^{* *}$ & 0.95 & $-1.47 * *$ & 0.36 \\
\hline Mixed & $2.37 * *$ & 0.59 & $0.76^{*}$ & 0.47 \\
\hline Herfindahl & - & - & $2.26^{* * *}$ & 0.33 \\
\hline Cohort1 & -0.04 & 0.45 & 0.27 & 0.37 \\
\hline Cohort2 & 0.18 & 0.19 & 0.33 & 0.20 \\
\hline Technology & $-0.75^{* *}$ & 0.27 & $-0.71 * *$ & 0.26 \\
\hline Alliance & 0.08 & 0.28 & 0.05 & 0.04 \\
\hline Industry & 0.04 & 0.04 & 0.01 & 0.04 \\
\hline US startup & -0.09 & 0.08 & -0.06 & 0.06 \\
\hline $\begin{array}{l}\text { Dummy variables } \\
\text { for product niches }\end{array}$ & \multicolumn{4}{|c|}{ YES } \\
\hline Observations & \multicolumn{2}{|c|}{270} & \multicolumn{2}{|c|}{270} \\
\hline LogLik. & \multicolumn{2}{|c|}{-924.11} & \multicolumn{2}{|c|}{-923.29} \\
\hline
\end{tabular}

Note: * and ** mean 0.10 and 0.05 level of significance, respectively 
Figure 1: Entry, exit and hazard function, 1989-2000

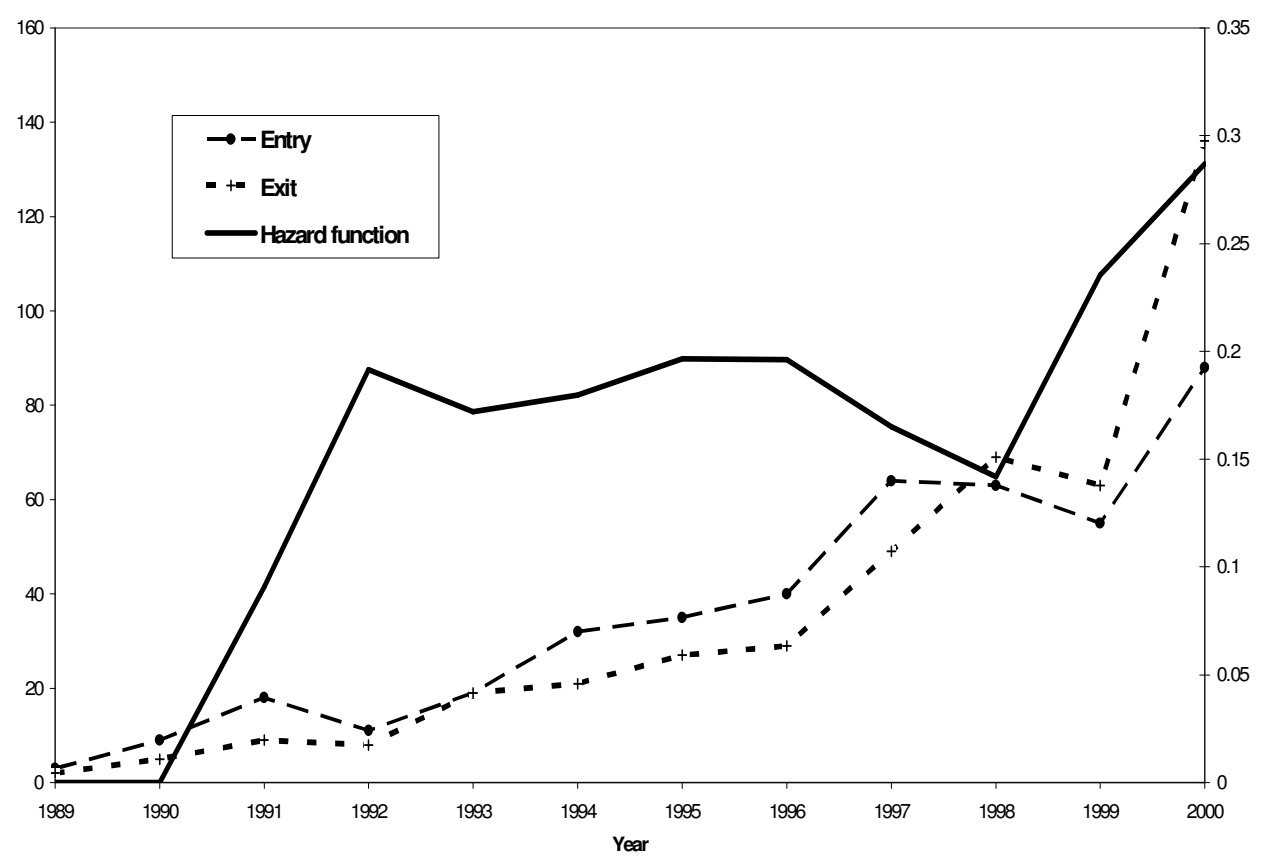

Notes: $\mathrm{X}$ axis years, $\mathrm{Y}_{1}$ axis (left) number of firms, $\mathrm{Y}_{2}$ axis (right) hazard 


\section{APPENDIX}

Table A. Robust OLS with Versioning and Portfolio as dependent variables

\begin{tabular}{|l|cc|cc|}
\hline Dependent variable & \multicolumn{2}{|c|}{ Versioning } & \multicolumn{2}{c|}{ Portfolio } \\
\hline Cohort1 & Coef. & Std. Err. & Coef. & Std. Err. \\
Cohort1 & -0.16 & 0.106 & 0.099 & 0.141 \\
Technology & 0.036 & 0.064 & 0.030 & 0.085 \\
Alliance & $0.162^{* *}$ & 0.078 & $0.613^{* *}$ & 0.104 \\
Industry & $0.056^{* *}$ & 0.017 & $0.087^{* *}$ & 0.023 \\
US startup & 0.000 & 0.000 & -0.00 & 0.000 \\
\hline Constant & 0.013 & 0.06 & 0.017 & 0.05 \\
Niche dummies & $0.331^{*}$ & 0.169 & 0.144 & 0.224 \\
Observations & \multicolumn{2}{|c|}{ Yes } & \multicolumn{3}{c|}{ Yes } \\
R square & \multicolumn{2}{|c|}{0.270} & \multicolumn{3}{c|}{0.368} \\
\hline
\end{tabular}

Note: $*$ and $* *$ mean 0.10 and 0.05 level of significance, respectively 